\title{
Penerapan Data Mining Menggunakan Algoritma K-Means Clustering Untuk Menentukan Strategi Promosi Mahasiswa Baru Universitas Bina Darma Palembang
}

\author{
M Reza Alhapizi ${ }^{1}$, Muhammad Nasir ${ }^{2}$, Irman Effendy ${ }^{3}$ \\ 1,2,3 Information System Departement, Universitas Bina Darma, Palembang, Indonesia \\ Email: 1reza.alhapizi1996@gmail.com, ²nasir@binadarma.ac.id, \\ 3irman.effendy@binadarma.ac.id
}

\begin{abstract}
Abstrak
Kemajuan luar biasa yang terus berlanjut dalam bidang data mining didorong oleh beberapa faktor salah satunya adalah pertumbuhan yang cepat dalam kumpulan data dan perkembangan yang hebat dalam kemampuan komputasi dan pengembangan kapasitas media penyimpanan. Data calon mahasiswa baru Universitas Bina Darma tak luput untuk dapat perhatian agar dapat dicari nilai emasnya. Banyak metode yang dapat digunakan untuk menggali nilai emas dari kumpulan data yang besar salah satunya adalah clustering. Teknik clustering dapat dijalankan dengan menggunakan salah satu Algoritma yang mudah diimplementasikan yaitu K-Means. Algoritma ini dapat dijalankan dengan menggunakan toolsRapid Miner dan hasilnya dapat dievaluasi sehingga dapat memperoleh metode promosi yang tepat.
\end{abstract}

Kata Kunci: clustering, k-Means, tools, Rapid Miner

\section{PENDAHULUAN}

Kemajuan teknologi informasi sekarang sudah semakin berkembang pesat dan hampir mencangkup di segala bidang kehidupan. Kemajuan tersebut menghasilkan tersedianya data yang sangat besar dan banyak mulai dari bidang industri, ekonomi, ilmu dan teknologi serta berbagai bidang kehidupan lainnya. Kemajuan luar biasa yang terus berlanjut dalam bidang data mining didorong oleh beberapa faktor (Larose, 2005) salah satunya adalah pertumbuhan yang cepat dalam kumpulan data dan perkembangan yang hebat dalam kemampuan komputasi dan pengembangan kapasitas media penyimpanan. 


\section{Journal of Software Engineering Ampera}

Vol. 1, No. 1, February 2020 e-ISSN: 2775-2488

https://journal-computing.org/index.php/journal-sea/index

Seperti halnya pada proses penerimaan mahasiswa baru dalam sebuah perguruan tinggi akan menghasilkan data-data baru berupa profil dari mahasiswa baru tersebut.Tahap selanjutnya adalah mahasiswa akan melakukan kegiatan pembelajaran di setiap semester, sehingga dapat diketahui data indeks prestasi mahasiswa pada akhir semester. Hal ini akan terjadi secara berulang pada sebuah perguruan tinggi. Apabila dilakukan pengolahan data pada kedua sumber data tersebut maka dapat diketahui berbagai informasi yang bermanfaat dalam membantu menentukan strategi promosi penerimaan mahasiswa baru tahun berikutnya. Pengolahan tersebut dapat dilakukan menggunakan salah satu metode Data Mining dengan algoritma K-Means Clustering. Menurut Pramudiono (2006), Data mining adalah serangkaian proses untuk menggali nilai tambah berupa pengetahuan yang selama ini tidak diketahui secara manual. Data yang jumlahnya besar tersebut perlu diolah oleh algoritma tersebut untuk diperoleh pengetahuan yang menunjang promosi. Hasil dari pengolahan tersebut akan sangat membantu pihak prodi atau fakultas dengan kondisi prodi atau fakultas tersebut masih belum lama berdiri, karena membutuhkan calon mahasiswa yang mempunyai potensi dalam bidang akademik dan pengaruhnya terhadap universitas adalah dapat meningkatkan jumlah mahasiswa dengan nilai akademik yang cukup tinggi.

Kondisi tersebut sama dengan kondisi yang dialami Prodi Teknik Informatika di Universitas Bina Darma Palembang. Data mahasiswa pada prodi tersebut perlu dilakukan pengolahan data dengan hasil yang menjelaskan tentang berbagai informasi-informasi mengenai persebaran wilayah mahasiswa sehingga informasi dari hasil pengolahan tersebut dapat membantu pihak Prodi Teknik Informatika Universitas Bina Darma Palembang untuk menentukan strategi promosi yang cocok dan tepat sasaran. Selain untuk membantu pihak Prodi Teknik Informatika Universitas Bina Darma Palembang, pengolahan data tersebut dilakukan agar dapat menentukan wilayah promosi yang tepat sasaran sehingga tidak terjadi penurunan jumlah mahasiswa pada tahun berikutnya.

Atribut yang tersedia pada data calon mahasiswa adalah kota asal mahasiswa, jurusan asal sekolah mahasiswa, jenis sekolah mahasiswa, jenis kelamin mahasiswa, agama mahasiswa dan jurusan sekolah mahasiswa. Berdasarkan atribut tersebut selanjutnya data akan dikelompokan menjadi asal kota mahasiswa, jurusan asal sekolah mahasiswa, jenis kelamin mahasiswa, agama mahasiswa dan jurusan sekolah mahasiswa menggunakan 


\section{Journal of Software Engineering Ampera}

Vol. 1, No. 1, February 2020 e-ISSN: 2775-2488

https://journal-computing.org/index.php/journal-sea/index

algoritma K-Means Cluster. Dari penjelasan diatas, maka penulis ingin melakukan penelitian "Penerapan DataMining Menggunakan Algoritma KMeans Clustering Untuk Menentukan Strategi Promosi Mahasiswa Baru Universitas Bina Darma Palembang".

\section{METODOLOGI PENELITIAN}

\subsection{Metode Pengumpulan}

Wawancara (Interview), Merupakan suatu pengumpulan data yang dilakukan dengan cara tanya jawab secara langsung. Wawancara dilakukan dengan pihak yang terkait, karyawan atau admin di Universitas Bina Darma Palembang mengenai Penerapan Data Mining menggunakan Algoritma KMeans Clustering untuk menentukan strategi promosi mahasiswa baru hingga tahap akhir penelitian.

Pengamatan (Observasi),Yaitu metode pengumpulan data dengan cara mengadakan tinjauan secara langsung ke objek yang diteliti. Observasi dilakukan langsung pada Universitas Bina Darma Palembang.

Studi Pustaka,Untuk mendapatkan data-data yang bersifat teoritis maka penulis melakukan pengumpulan data dengan cara membaca dan mempelajari buku-buku, jurnal penelitian, makalah ataupun referensi lain yang berhubungan dengan masalah yang dibahas.

\subsection{PreProcessing}

Tahap Pra pengolahan meliputi tahapan integrasi atau penggabungan data seluruh nya dan juga pembersihan data yang mana hasilnya akan lebih baik ketika dilakukan clustering nantinya.

1) Integrasi Data, data yang diperoleh setelah digabungkan menjadi satu tabel data yang besar sebagai satu kesatuan. Data penerimaan mahasiswa baru dari tahun 2014 sampai dengan 2017 digabung menjadi satu data besar, tidak terpisah serta baik untuk diclustering. Dan data yang sudah penulis terima sudah dalam bentuk sudah digabung atau terintegrasi.

2) Cleaning Data, data yang telah digabung akan dilakukan pembersihan, membuang data yang kosong dan memastikan data tersebut relevan atau, terkait satu sama lain. 


\section{Journal of Software Engineering Ampera}

Vol. 1, No. 1, February 2020 e-ISSN: 2775-2488

https://journal-computing.org/index.php/journal-sea/index

Data sebelum dilakukan cleaning, jika ada tampak data yang kosong untuk beberapa kolom. Record yang terdapat hal demikian yang layak dihapus, agar data yang diolah nanti mempunyai informasi yang baik. Data yang kami peroleh, memang memiliki sejumlah data yang kosong atau yang diisi dengan tulisan NULL sehingga cleaning sangat perlu dilakukan. Adanya kemungkinan nilai NULL atau kosong dikarenakan kurang lengkapnya data yang terima dari perorangan dari calon mahasiswa baru Universitas Bina Darma.:

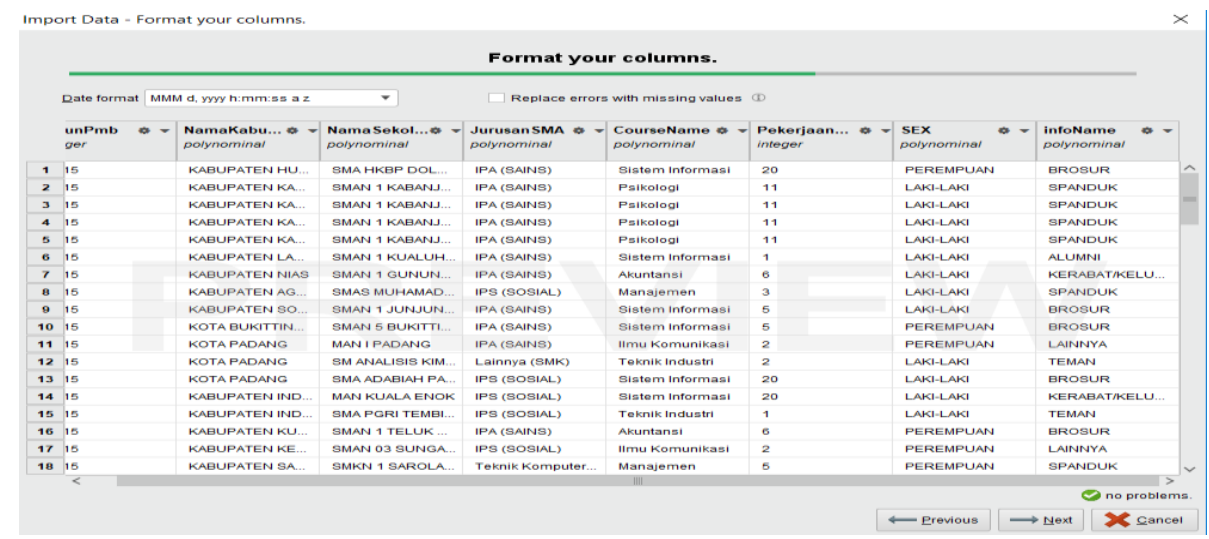

Gambar 1. ReFormatDataset

\section{Penerapan Metode K-Means menggunakan Aplikasi Rapid Miner}

1. Statistik Data Penerimaan Mahasiswa Baru Jurusan Teknik Informatika. Setelah data berhasil dilakukan import, rapid miner secara otomatis telah melakukan analisa statistika. Hasil statistik data penerimaan mahasiswa baru yang berhasil diperoleh adalah sebagai berikut:

a. Atribut InfoName

Berdasarkan data statistik diperoleh yang tertinggi jatuh pada Brosur. Mayoritas calon mahasiswa baru mengetahui Universitas Bina Darma dari Brosur. Sedangkan yang terendah yaitu informasi dari twitter.

\begin{tabular}{|c|c|c|c|c|}
\hline Index & Nominal value & Absolute count & \multicolumn{2}{|c|}{ Fraction } \\
\hline 1 & BROSUR & 186 & \multicolumn{2}{|l|}{0.254} \\
\hline 2 & KERABAT/KELUARGA & 173 & \multicolumn{2}{|l|}{0.237} \\
\hline 3 & TEMAN & 126 & \multicolumn{2}{|l|}{0.172} \\
\hline 4 & LAINNYA & 93 & \multicolumn{2}{|l|}{0.127} \\
\hline 5 & ALUMNI & 80 & \multicolumn{2}{|l|}{0.109} \\
\hline 6 & DOSEN / KARYAWAN B... & 24 & \multicolumn{2}{|l|}{0.033} \\
\hline 7 & SPANDUK & 23 & \multicolumn{2}{|l|}{0.031} \\
\hline 8 & KORAN/MAJALAH & 12 & 0.016 & $\checkmark$ \\
\hline & & & \multicolumn{2}{|c|}{ \& close } \\
\hline
\end{tabular}

Gambar 2. Data dan Ringkasan Statistikan Atribut InfoName 


\section{Journal of Software Engineering Ampera}

Vol. 1, No. 1, February 2020 e-ISSN: 2775-2488

https://journal-computing.org/index.php/journal-sea/index

b. Atribut NamaKabupaten

Data statistik berkata bahwa calon mahasiswa/i paling banyak diperoleh dari orang-orang yang berasal dari Palembang. Dan yang paling sedikit berasal dari kota pematang siantar. Berikut ringkasan statistik jumlah mahasiswa/i berdasarkan NamaKabupaten:

\begin{tabular}{|c|c|c|c|c|}
\hline \multicolumn{4}{|c|}{ (III) Nominal values } & \multirow[t]{2}{*}{$\times$} \\
\hline Index & Nominal value & Absolute count & Fraction & \\
\hline 1 & KOTA PALEMBANG & 299 & 0.409 & $\hat{\imath}$ \\
\hline 2 & KABUPATEN BANYUASIN & 57 & 0.078 & \\
\hline 3 & KABUPATEN MUSI BANYUASIN & 52 & 0.071 & \\
\hline 4 & KABUPATEN OGAN KOMERING ILIR & 37 & 0.051 & \\
\hline 5 & KABUPATEN MUARA ENIM & 36 & 0.049 & \\
\hline 6 & KABUPATEN OGAN ILIR & 36 & 0.049 & \\
\hline 7 & KABUPATEN LAHAT & 34 & 0.047 & \\
\hline 8 & KABUPATEN OKU TIMUR & 22 & 0.030 & $\checkmark$ \\
\hline
\end{tabular}

Gambar 3. Statistik Jumlah Mahasiswa Baru Berdasarkan kabupaten mereka berasal

c. Atribut Asal Sekolah

Data statistik kali ini menunjukkan sesuatu yang sedikit berbeda, dari data yang diperoleh, dari mayoritas data, kebanyakan asal sekolah dari kota Palembang. Dan yang paling sedikit adalah berasal dari smkn batam dan jambi. Berikut data statistik secara ringkas dan menyeluruh:

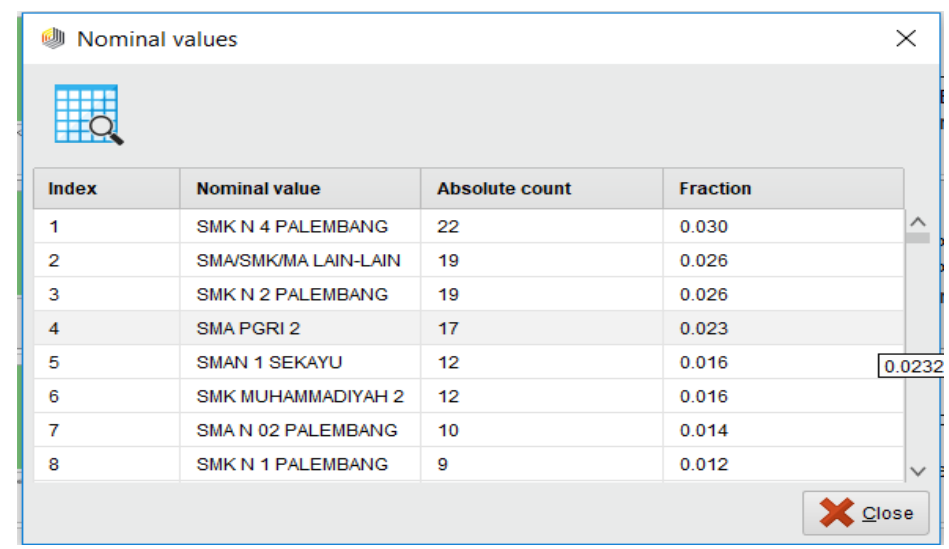

Gambar 4. Ringkasan jumlah mahasiswa baru berdasarkan asal sekolah 


\section{Journal of Software Engineering Ampera}

Vol. 1, No. 1, February 2020 e-ISSN: 2775-2488

https://journal-computing.org/index.php/journal-sea/index

\section{HASIL DAN PEMBAHASAN}

\subsection{Centroid K-Means}

Atribut fitur yang digunakan pada pengujian ini adalah infoName, NamaKabupaten, NamaSekolah, PekerjaanAyah. Atribut ini atribut yang merupakan bagian referensi penulis untuk menentukan strategi promosi yang tepat untuk ke depannya setelah melihat hasil cluster nantinya. Berikut tampilan data terakhir yang digunakan:

\begin{tabular}{|c|c|c|c|c|}
\hline 橎 包 & $\hookrightarrow \subset$ & 国早 & & \\
\hline $\begin{array}{l}\text { Row } \\
\text { No. }\end{array}$ & $\begin{array}{c}\text { infoName } \\
\text { (polynominal) } \\
\text { regular }\end{array}$ & $\begin{array}{c}\text { NamaKabupaten } \\
\text { (polynominal) } \\
\text { regular }\end{array}$ & $\begin{array}{c}\text { NamaSekolah } \\
\text { (polynominal) } \\
\text { regular }\end{array}$ & $\begin{array}{l}\text { PekerjaanAyah } \\
\text { (integer) } \\
\text { regular }\end{array}$ \\
\hline 1 & TEMAN & KABUPATEN BANYUAS... & SMAN 1 TANJUNG LAGO & 0 \\
\hline 2 & LAINNYA & KABUPATEN OKU TIM... & SMA NEGERI 2 SEMENDAWAI BARAT & 0 \\
\hline 3 & BROSUR & KOTA LUBUK LINGGAU & SMAVSMKIMA LAIN-LAIN & 0 \\
\hline 4 & BROSUR & KOTA PALEMBANG & SMAN 18 PALEMBANG & 0 \\
\hline 5 & TEMAN & KOTA PALEMBANG & SMK BINA JAYA PALEMBANG & 0 \\
\hline 6 & KERABAT/KELUAR... & KOTA PALEMBANG & SMAVSMKIMA LAIN-LAIN & 0 \\
\hline 7 & ALUMNI & KOTA JAKARTA TIMUR & SMK MITRA KENCANA & 0 \\
\hline 8 & TEMAN & KABUPATEN OGAN KO... & SMAN 1 AIR SUGIHAN & 0 \\
\hline 9 & NULL & KOTA PALEMBANG & SMA N 08 PALEMBANG & 0 \\
\hline 10 & KERABAT/KELUAR... & KOTA PALEMBANG & SMAPGRI 2 & 0 \\
\hline 11 & BROSUR & KOTA PALEMBANG & SMA PEMBINA & 0 \\
\hline 12 & DOSEN / KARYAWA... & KOTA PALEMBANG & SMAPGRI 2 & 0 \\
\hline 13 & ALUMNI & KOTA LUBUK LINGGAU & SMK YADIKA LUBUKLINGGAU & 0 \\
\hline 14 & BROSUR & KOTA PALEMBANG & SMAN 09 PALEMBANG & 0 \\
\hline 15 & BROSUR & KABUPATEN BANYUAS... & SMAN 1 MUARA PADANG & 0 \\
\hline 16 & LAINNYA & KOTA PALEMBANG & SMKN 4 PALEMBANG & 0 \\
\hline
\end{tabular}

Gambar 5. Atribut terpilih untuk dijadikan atribut fitur bagi metode K-Means

\subsection{Analisa Algoritma K-Means}

Menurut Santosa (2007), langkah-langkah melakukan Clustering dengan metode K-Means adalah sebagai berikut:

1) Pilih jumlah Cluster $\mathrm{K}$

2) Inisialisasi K pusat Cluster ini bisa di lakukan dengan berbagai cara. Namun yang palig sering di lakukan adalah dengan cara random. Pusat-pusat Cluster di beri nilai awal dengan angkah-angkah random

3) Alokasikan semua data atau objek ke Cluster terdekat. Kedekatan dua objek di tentukan berdasarkan jarak kedua objek tersebut. Demikian juga kedekatan suatu data ke Cluster tertentu di tentukan jarak antara data dengan pusat Cluster. Jarak paling antara satu data dengan satu Cluster tertentu akan menentukan suatu data masuk dalam Cluster mana. 


\section{Journal of Software Engineering Ampera}

Vol. 1, No. 1, February 2020 e-ISSN: 2775-2488

https://journal-computing.org/index.php/journal-sea/index

Untuk menghitung jarak semua data ke setiap titik pusat Cluster dapat menggunakan teori jarak Euclidean yang di rumuskan sebagai berikut:

$D(i, j)=\sqrt{(X x i-X 1 j)+(X 2 i-X 2 j)+\ldots .+(X k i+X k j)}$

Dimana:

$D(i, j)=$ jarak data ke $i$ ke pusat cluster $j$

$X k i=$ Data ke $i$ atribut data ke $k$

$X k j=$ Titik pusat ke $j$ pada atribut $k$

1) Hitung keembali pusat cluster dengan keanggotaan cluster yang sekarang. Pusat cluster adalah rata-rata dari semua data atau objek dalam cluster tertentu. Jika di kehendaki bisa juga menggunakan medan dari cluster tersebut. Jadi rata-rata (mean) bukan satu-satunya ukuran yang bisa di pakai.

2) Tugaskan lagi setiap objek memakai pusat cluster yang baru. Jika pusat cluster tidak berubah lagi maka proses clustering selesai. Atau, kembali ke langkah no 3 sampai pusat cluster tidak berubah lagi.

\begin{tabular}{|c|c|c|c|c|}
\hline No & NamaKabupaten & NamaSelølah & Pekerjaandyah & infoName \\
\hline 1 & KOTA PALEMBAHG & SMA PGRI 2 & .0 & KERABAT/KELUARGA \\
\hline 2 & $\begin{array}{l}\text { KABUPATEN } \\
\text { BAHYUASIN }\end{array}$ & $\begin{array}{l}\text { SMA SATRIA HUSANTARA } \\
\text { BETUHG }\end{array}$ & 1.0 & TEMAN \\
\hline 3 & KABUPATEN LAHAT & SMAH 2 LAHAT & 1.0 & BROSUR \\
\hline 4 & $\begin{array}{l}\text { KABUPATEN MUARA } \\
\text { ENIM }\end{array}$ & SMA FGRI GELUMBAHG & 1.0 & LAINHYA \\
\hline 5 & $\begin{array}{l}\text { KABUPATEN MUARA } \\
\text { ENIM }\end{array}$ & SMKH 1 MUARA ENIM & 1.0 & KORAH/MAJALAH \\
\hline 6 & $\begin{array}{l}\text { KABUPATEN MUARA } \\
\text { ENIM }\end{array}$ & SMKN 1 MUARA ENIM & 1.0 & TEMAN \\
\hline 7 & $\begin{array}{l}\text { KABUPA TEN MUARA } \\
\text { ENIM }\end{array}$ & SMKN 2 MUARA ENIM & 1.0 & TEMAN \\
\hline 8 & $\begin{array}{l}\text { KABUPATEN MUSI } \\
\text { BANYUASIN }\end{array}$ & SMAN I SEKAYU & 1.0 & TEMAN \\
\hline 9 & $\begin{array}{l}\text { KABUPATEN MUSI } \\
\text { BANYUASIN }\end{array}$ & SMAN I SEKAYU & 1.0 & TEMAN \\
\hline 10 & $\begin{array}{l}\text { KABUPATEN MUSI } \\
\text { BANYUASIN }\end{array}$ & SMAN 1 SEKAYU & 1.0 & KERABA T/KELUARGA \\
\hline 11 & $\begin{array}{l}\text { KABUPATEN MUSI } \\
\text { BANYUASIN }\end{array}$ & SMAN 1 SUHGAI LILIN & 1.0 & BROSUR \\
\hline 12 & $\begin{array}{l}\text { KABUPATEN MUSI } \\
\text { BANYUASIN }\end{array}$ & SMKN 2SEKAYU & 1.0 & TEMAN \\
\hline 13 & $\begin{array}{l}\text { KABUPA TEH OGAH } \\
\text { ILIR }\end{array}$ & $\begin{array}{l}\text { SMKN INDRALAYA } \\
\text { SELATAN }\end{array}$ & 1.0 & KERABA T/KELUAFGA \\
\hline 14 & $\begin{array}{l}\text { KABUPATEH OGAH } \\
\text { KOMERING ILIR }\end{array}$ & SMAN 1 PAMPANGAH & 1.0 & KERABAT/KELUAFGA \\
\hline 15 & $\begin{array}{l}\text { KABUPATEN OGAH } \\
\text { KOMERING ILIR }\end{array}$ & SMAH 2 KAYUAGUHG & 1.0 & ALUMHI \\
\hline$\cdots$ & $\cdots$ & $\cdots$ &. & $\cdots$ \\
\hline 730 & KOTA PALEMBAHG & SMASMKMA LAIN-LAIN & 20.0 & BROSUR \\
\hline 731 & KOTA PALEMBAHG & SMA SYAKYAKIRTI & 20.0 & LAINHYA \\
\hline
\end{tabular}

Gambar 6. Data Calon Mahasiswa Universitas Bina Darma 


\section{Journal of Software Engineering Ampera}

Vol. 1, No. 1, February 2020 e-ISSN: 2775-2488

https://journal-computing.org/index.php/journal-sea/index

Untuk melakukan perhitungan K-Means, data yang dapat diolah harus dalam bentuk angka (numerik). Jika data masih dalam bentuk polynomial atau nominal seperti data pada atribut NamaKabupaten, NamaSekolah dan InfoName, maka perlu dibuat nilai permisalan atau inisialisasi nilai baru.

Maka dari itu langkah selanjutnya adalah melakukan inisialisasi data. Inisialisasi data dilakukan berdasarkan frekuensi data yang terdapat dalam setiap instansi dari atribut. Inisialisasi data dari atribut NamaKabupaten adalah sebagai berikut:

\begin{tabular}{|c|c|c|c|}
\hline No & NamaKabupaten & Frekwensi & Intial Nilai \\
\hline $\mathbf{1}$ & KOTA PALEMBAHG & 299.0 & 1 \\
\hline 2 & KABUPATEH BANYUASIN & 57.0 & 2 \\
\hline 3 & KABUPATEN MUSI BANYUASIN & 52.0 & 3 \\
\hline 4 & KABUPATEH OGAH KOMERIHGILIR & 37.0 & 4 \\
\hline 5 & KABUPATEH MUARA EHIM & 36.0 & 5 \\
\hline 6 & KABUPA TEN OGAH ILIR & 36.0 & 6 \\
\hline 7 & KABUPATEH LAHAT & 34.0 & 7 \\
\hline 8 & KABUPATEN OKU TIMUR & 22.0 & 8 \\
\hline 9 & KABUPA TEH PALI & 21.0 & 9 \\
\hline 10 & KOTA PRABUMULIH & 21.0 & 10 \\
\hline 11 & KOTA PAGAR ALAM & 18.0 & 11 \\
\hline 12 & KABUPATEH OGAH KOMERIHG ULU & 17.0 & 12 \\
\hline 13 & KABUPATEN OKU SELATAH & 16.0 & 13 \\
\hline 14 & KOTA LUBUK LINGGAU & 13.0 & 14 \\
\hline 15 & KABUPATEH EMPATLAWAHG & 8.0 & 15 \\
\hline
\end{tabular}

Gambar 7. Data Nama Kabupaten dan Frekuensi Kejadian

Kota Palembang memiliki frekuensi tertinggi dalam data yaitu memiliki 299 kejadian, maka dari itu diberi nilai 1. Kabupaten Banyuasin memiliki peringkat kedua terbanyak kemudian diberi nilai inisial 2 dan berikut seterusny. Setelah NamaKabupaten selanjutnya yang perlu diinisialisasi adalah Nama sekolah. Inisialisasi data dari atribut NamaSekolah adalah sebagai berikut:

\begin{tabular}{|c|c|c|c|}
\hline No & NamaSelolah & Frekwensi & Inisial Data \\
\hline $\mathbf{l}$ & SMK H 4 PALEMBAHG & 22.0 & 1 \\
\hline 2 & SMASMKMMA LAIN-LAIN & 19.0 & 2 \\
\hline 3 & SMKH 2 PALEMBAHG & 19.0 & 3 \\
\hline 4 & SMA PGRI 2 & 17.0 & 4 \\
\hline 5 & SMAH I SEKAYU & 12.0 & 5 \\
\hline 6 & SMK MUHAMMADTYAH 2 & 12.0 & 6 \\
\hline 7 & SMA N 02 PALEMBAHG & 10.0 & 7 \\
\hline 8 & SMK H 1 PALEMBAHG & 9.0 & 8 \\
\hline 9 & SMKH I MUARA ENIM & 9.0 & 9 \\
\hline 10 & SMA N 04 PALEMBANG & 8.0 & 10 \\
\hline
\end{tabular}

Gambar 7. Data Nama Sekolah dan Frekuensi Kejadian 


\section{Journal of Software Engineering Ampera}

Vol. 1, No. 1, February 2020 e-ISSN: 2775-2488

https://journal-computing.org/index.php/journal-sea/index

Dan yang terakhir adalah inisialisasi atribut InfoName. Atribut penghasil sudah terlebih dahulu nilainya berada dalam nilai numerik sehingga tidak dibutuhkan proses inisialisasi. Inisialiasi data untuk atribut InfoName adalah sebagai berikut:

\begin{tabular}{|c|l|c|c|}
\hline No & infoName & Frekuensi & Inisial Data \\
\hline $\mathbf{1}$ & BROSUR & 186.0 & 1 \\
\hline $\mathbf{2}$ & KERABA T/KELUARGA & 173.0 & 2 \\
\hline $\mathbf{3}$ & TEMAN & 126.0 & 3 \\
\hline $\mathbf{4}$ & LAINHYA & 93.0 & 4 \\
\hline $\mathbf{5}$ & ALUMHI & 80.0 & 5 \\
\hline $\mathbf{6}$ & DOSEN/KARYAWAH BINA DARMA & 24.0 & 6 \\
\hline $\mathbf{7}$ & SPANDUK & 23.0 & 7 \\
\hline $\mathbf{8}$ & KORAN/MAJALAH & 12.0 & 8 \\
\hline $\mathbf{9}$ & INSTAGRAM & 5.0 & 9 \\
\hline $\mathbf{1 0}$ & TELEVISI & 5.0 & 10 \\
\hline $\mathbf{1 1}$ & FACEBOOK & 3.0 & 11 \\
\hline $\mathbf{1 2}$ & RADIO & 1.0 & 12 \\
\hline
\end{tabular}

Gambar 8. Data InfoName dan Frekuensi Kejadian

Berdasarkan inisialiasi data dari ketiga atribut yaitu NamaKabupaten, NamaSekolah, InfoName sebagaimana di atas maka data yang akan diproses oleh metode K-Means menjadi sebagai berikut:

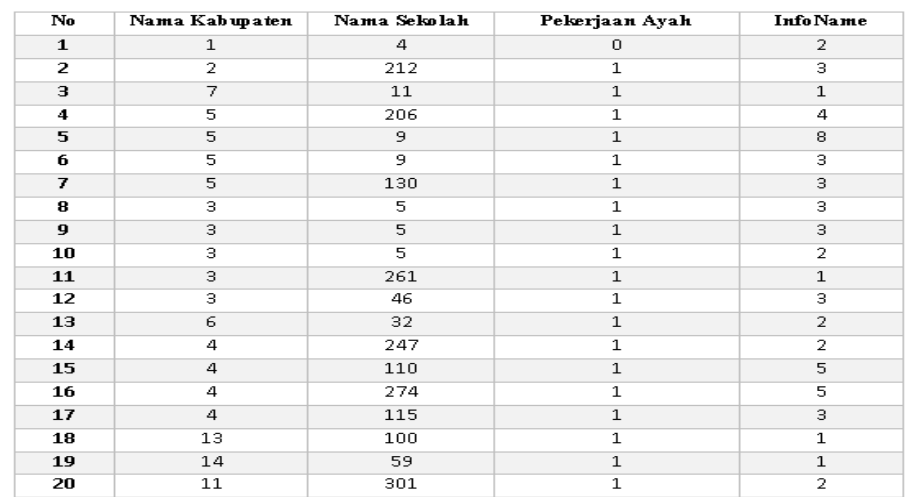

Gambar 9. Data Calon Mahasiswa Setelah diinisialisasi

Setelah data berhasil diubah menjadi tipe numerik maka langkah-langkah atau tahapan-tahapan K-Means dapat diterapkan sebagai berikut:

1) Menentukan Jumlah Cluster, peneliti memilih 2 cluster $(k=2)$ yang akan dibuat. Banyaknya cluster harus lebih kecil dari pada banyaknya data $(k<n)$.

2) Menentukan Centroid Tiap Cluster, Untuk menentukan centroid awal (initial centroid) banyak metode yang dapat digunakan. Disini metode 


\section{Journal of Software Engineering Ampera}

Vol. 1, No. 1, February 2020 e-ISSN: 2775-2488

https://journal-computing.org/index.php/journal-sea/index

yang digunakan adalah mengambil data dari data sumber, secara acak atau random. Berikut data centroid tersebut.

\begin{tabular}{|l|c|c|c|c|}
\hline & NamaKabupaten & NamaSekolah & PenghasilanAyah & InfoName \\
\hline Centroid 1 (c1) & 1 & 1 & 1 & 4 \\
\hline Centroid 2 (c2) & 29 & 332 & 1 & 8 \\
\hline
\end{tabular}

Gambar 10. Data Inisial Centroid

a. Menghitung jarak data dengan centroid, Untuk menghitung jarak data dengan centroid menggunakan rumus euclidean distance. Rumus Euclidean Distance adalah sebagai berikut:

$$
\begin{aligned}
& d\left(x_{j}, c_{j}\right)=\sqrt{\sum_{j=1}^{n}\left(x_{j}-c_{j}\right)^{2}} \\
& d=\text { jarak } \\
& j=\text { banyaknya data } \\
& c=\text { centroid } \\
& x=\text { data } \\
& c=\text { centroid }
\end{aligned}
$$

Jarak data dengan centroid 1 adalah:

$$
\begin{aligned}
\mathrm{d}(1,1) & =\sqrt{(x 1-p 1)^{2}+(x 2-p 2)^{2}+(x 3-p 3)^{2}+(x 4-p 4)^{2}} \\
& =\sqrt{(1-1)^{2}+(4-1)^{2}+(0-1)^{2}+(2-4)^{2}} \\
& =3.7416 \\
\mathrm{~d}(2,1) & =\sqrt{(x 1-p 1)^{2}+(x 2-p 2)^{2}+(x 3-p 3)^{2}+(x 4-p 4)^{2}} \\
& =\sqrt{(2-1)^{2}+(212-1)^{2}+(1-1)^{2}+(3-4)^{2}} \\
& =211.004
\end{aligned}
$$

Dan seterusnya sampai data ke 731, Selanjutnya dihitung jarak data dengan centroid 2 adalah:

$$
\begin{aligned}
\mathrm{d}(1,2) & =\sqrt{(x 1-p 1)^{2}+(x 2-p 2)^{2}+(x 3-p 3)^{2}+(x 4-p 4)^{2}} \\
& =\sqrt{(1-29)^{2}+(4-332)^{2}+(0-1)^{2}+(2-8)^{2}} \\
& =329.2491 \\
\mathrm{~d}(2,2) & =\sqrt{(x 1-p 1)^{2}+(x 2-p 2)^{2}+(x 3-p 3)^{2}+(x 4-p 4)^{2}} \\
& =\sqrt{(4-29)^{2}+(3-332)^{2}+(1-1)^{2}+(6-8)^{2}} \\
& =123.101
\end{aligned}
$$

Dan seterusnya sampai data ke 731 


\section{Journal of Software Engineering Ampera}

Vol. 1, No. 1, February 2020 e-ISSN: 2775-2488

https://journal-computing.org/index.php/journal-sea/index

b. Hasil Perhitungan Jarak

\begin{tabular}{|l|l|l|}
\hline No & \multicolumn{1}{|c|}{ Jarak C1 } & \multicolumn{1}{|c|}{ Jarak C2 } \\
\hline 1 & 3.741657387 & 329.2491458 \\
\hline 2 & 211.0047393 & 123.1015841 \\
\hline 3 & 12.04159458 & 321.8291472 \\
\hline 4 & 205.0390207 & 128.3277055 \\
\hline 5 & 9.797958971 & 323.8904136 \\
\hline 6 & 9 & 323.9290046 \\
\hline 7 & 129.0658747 & 203.482186 \\
\hline 8 & 4.582575695 & 328.0701145 \\
\hline 9 & 4.582575695 & 328.0701145 \\
\hline 10 & 4.898979486 & 328.0868787 \\
\hline 11 & 260.0249988 & 75.93418203 \\
\hline 12 & 45.0555213 & 287.2229099 \\
\hline 13 & 31.46426545 & 300.9401934 \\
\hline 14 & 246.0264213 & 88.8031531 \\
\hline 15 & 109.0458619 & 223.4233649 \\
\hline 16 & 273.0183144 & 63.22973984 \\
\hline 17 & 114.0438512 & 218.4925628 \\
\hline 18 & 99.76973489 & 232.656399 \\
\hline 19 & 59.51470407 & 273.5013711 \\
\hline 20 & 300.1732833 & 36.34556369 \\
\hline
\end{tabular}

Gambar 11. Data jarak centroid terhadap data

Hasil jarak tersebut digunakan untuk menentukan pada cluster mana suatu data terkelompok. Data dikelompokkan menurut nilai jarak terkecil. Misal data1 jarak terkecil jatuh pada C1 maka data 1 termasuk anggota cluster 1. Maka Data Sekarang setelah berhasil dipetakan ke dalam cluster menurut jarak yang sudah diperoleh.

Tabel 1. Cluster menurut jarak

\begin{tabular}{|c|c|c|c|c|c|c|}
\hline No & $\begin{array}{c}\text { Nama } \\
\text { Kab uaten }\end{array}$ & Nama Sekolah & $\begin{array}{c}\text { Pekerjaan } \\
\text { Ayah }\end{array}$ & Info Name & Cluster l & Cluster 2 \\
\hline 1 & 1 & 4 & 0 & 2 & $*$ & \\
\hline 2 & 2 & 212 & 1 & 3 & & $*$ \\
\hline 3 & 7 & 11 & 1 & 1 & $*$ & \\
\hline 4 & 5 & 206 & 1 & 4 & & $*$ \\
\hline 5 & 5 & 9 & 1 & 8 & $*$ & \\
\hline 6 & 5 & 9 & 1 & 3 & $*$ & \\
\hline 7 & 5 & 130 & 1 & 3 & $*$ & \\
\hline 8 & 3 & 5 & 1 & 3 & $*$ & \\
\hline 9 & 3 & 5 & 1 & 3 & $*$ & \\
\hline
\end{tabular}




\section{Journal of Software Engineering Ampera}

Vol. 1, No. 1, February 2020 e-ISSN: 2775-2488

https://journal-computing.org/index.php/journal-sea/index

\begin{tabular}{|l|l|l|l|l|l|l|}
\hline 10 & 3 & 5 & 1 & 2 & ${ }^{*}$ & \\
\hline 11 & 3 & 261 & 1 & 1 & & $*$ \\
\hline 12 & 3 & 46 & 1 & 3 & ${ }^{*}$ & \\
\hline 13 & 6 & 32 & 1 & 2 & ${ }^{*}$ & \\
\hline 14 & 4 & 247 & 1 & 2 & & $*$ \\
\hline 15 & 4 & 110 & 1 & 5 & ${ }^{*}$ & \\
\hline 16 & 4 & 274 & 1 & 5 & & $*$ \\
\hline 17 & 4 & 115 & 1 & 3 & $*$ & \\
\hline 18 & 13 & 100 & 1 & 1 & $*$ & \\
\hline 19 & 14 & 59 & 1 & 1 & $*$ & \\
\hline 20 & 11 & 301 & 1 & 2 & & $*$ \\
\hline
\end{tabular}

Cluster 0 memiliki lebih dari 600 anggota, dan cluster 1 memiliki lebih dari 100 anggota. Dengan melihat hasil pada tabel tersebut diperoleh total anggota Cluster 0 lebih banyak dari total anggota cluster 1 , dan hasil ini tidaklah berbeda dengan hasil yang diolah dari tools rapid miner.

\section{c. Hasil evaluasi (Evaluation Result)}

Setelah melihat hasil dari cluster model diperoleh pada cluster pertama yaitu cluster 0 memiliki 616 anggota yang terkelompok. Sedangkan cluster kedua yaitu cluster 1 memiliki 115 anggota yang terkelompok. Jika dilihat cluster pertama (cluster 0) memiliki jumlah anggota yang sangat banyak menandakan orang-orang yang mendapatkan informasi dari brosur,teman, kerabat dan lain sebagainya. Sedangkan cluster kedua (cluster 1) memiliki paling sedikit anggota yang terkelompok, jika dilihat dari kelompok datanya cluster 0 cluster yang mayoritas mahasiswa/I diperoleh dari strategi brosur, teman dan kerabat.

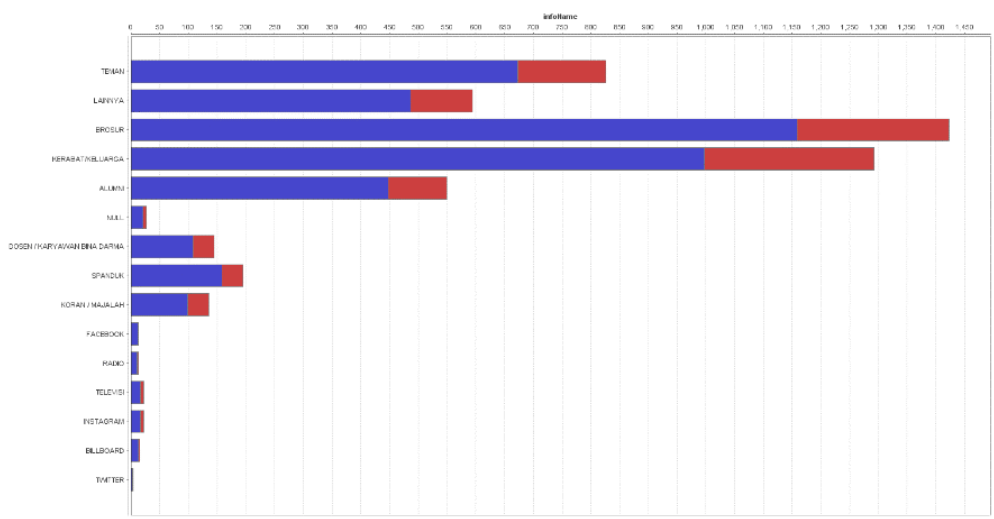

Gambar 12. Visualisasi Pembagian Anggota Cluster 


\section{Journal of Software Engineering Ampera}

Vol. 1, No. 1, February 2020 e-ISSN: 2775-2488

https://journal-computing.org/index.php/journal-sea/index

Sudah terlihat sekali bahwa ketiga strategi ini adalah strategi yang paling baik dalam mempromosikan lembaga agar memperoleh lebih banyak lagi mahasiswa/l yang meniti ilmu di Universitas Bina Darma. Sehingga yang dapat disimpulkan dari keanggotaan cluster tersebut didapati strategi yang bagus untuk diterapkan sekarang dan seterusnya adalah

1) Menyebar brosur, membuat desain yang menarik dan menyebarkannya ke berbagai macam tempat, tentu memiliki dampak yang besar bagi banyaknya jumlah penerimaan mahasiswa baru yang akan datang.

2) Promosi ke berbagai daerah, dengan menyebarkan informasi ke daerahdaerah, memungkinkan para calon mahasiswa/i mengetahui informasi tentang Universitas Bina Darma dengan lebih baik.

\section{KESIMPULAN}

Akhirnya sudah sampai kita pada akhir dari laporan. Semua langkah-langkah yang telah diarahkan pada metode CRISM-DM dan hasil dari menggunakan metode clustering $K$-Means maka jatuhlah kepada suatu kesimpulan sebagai berikut:

1) Setelah dilakukan pengelompokkan data mahasiswa berdasarkan persebaran kabupaten, asal sekolah, penghasilan ayah dan informasi maka diperoleh suatu gagasan bahwa cluster yang jumlahnya terbanyak adalah strategi promosinya dengan menggunakan brosur dan promosi dari teman atau kerabat dekat.

2) Fungsi media sosial belum begitu efektif dilihat dari frekuensi statistik calon mahasiswa baru dari instansi atribut ini.

3) Strategi promosi yang selanjutnya perlu dipertahankan adalah brosur, berikutnya informasi dari teman atau kerabat dan keikutsertaan karyawan atau dosen dalam mempromosikannya. Dan Media sosial seharusnya menjadi sumber informasi terbaru dan terluas bagi calon mahasiswa baru nantinya.

\section{DAFTAR PUSTAKA}

Fauziah Nur, Dkk. 2017."Penerapan Algoritma K-MEANS Pada Siswa Baru Sekolah Menengah Kejuruan Untuk Clustering Jurusan". https://jurnal.uisu.ac.id/index.php/infotekjar/article/view/70 (4 April 2018)

Y. Agusta, "K-Means Penerapan, Permasalahan dan Metode Terkait," Jurnal Sistem dan Informatika, vol. 3, pp. 47-60, Pebruari 2007. 


\section{Journal of Software Engineering Ampera}

Vol. 1, No. 1, February 2020 e-ISSN: 2775-2488

https://journal-computing.org/index.php/journal-sea/index

Jiawei Han, Micheline Kamber.2011.Data Mining: Concepts and Techniques, $3^{\text {rd }}$ ed. The Morgan Kaufmann Series in Data Management Systems.Morgan Kaufmann

Connolly, Thomas dan Begg, Carolyn. (2010). Database Systems A Practical. Approach to Design, Implementation, and Management. Fifth Edition. Boston: Pearson Education.

Kurt Thearling, dkk. 1999.Building Data Mining Applications for CRM. McGraw-Hill,. Inc., New

Dunham, Margaret H.2003. "Data Mining: Introductory and Advanced Topics". Pearson Education, Inc.

Mehmed Kantardzic.2012."Data Mining: Concepts, Models, Methods, and Algorithms". Wiley-IEEE Press

Vercellis, Bernadth. (2009), Sistem Informasi, Lokomedia, Yogyakarta

Larose D, T., 2005, Discovering knowledge in data : an introduction to data mining, Jhon Wiley \& Sons Inc

Charles Lamb, W.et.al. 2001. Pemasaran. Edisi Pertama, Salemba Empat: Jakarta.

Kotler, Philip and Gary Armstrong. 2012. Prinsip-prinsip Pemasaran. Edisi 13 Jilid I. Jakarta: Erlangga. 